\title{
Transpapillary removal of migrated magnets after magnetic compression biliary anastomosis
}

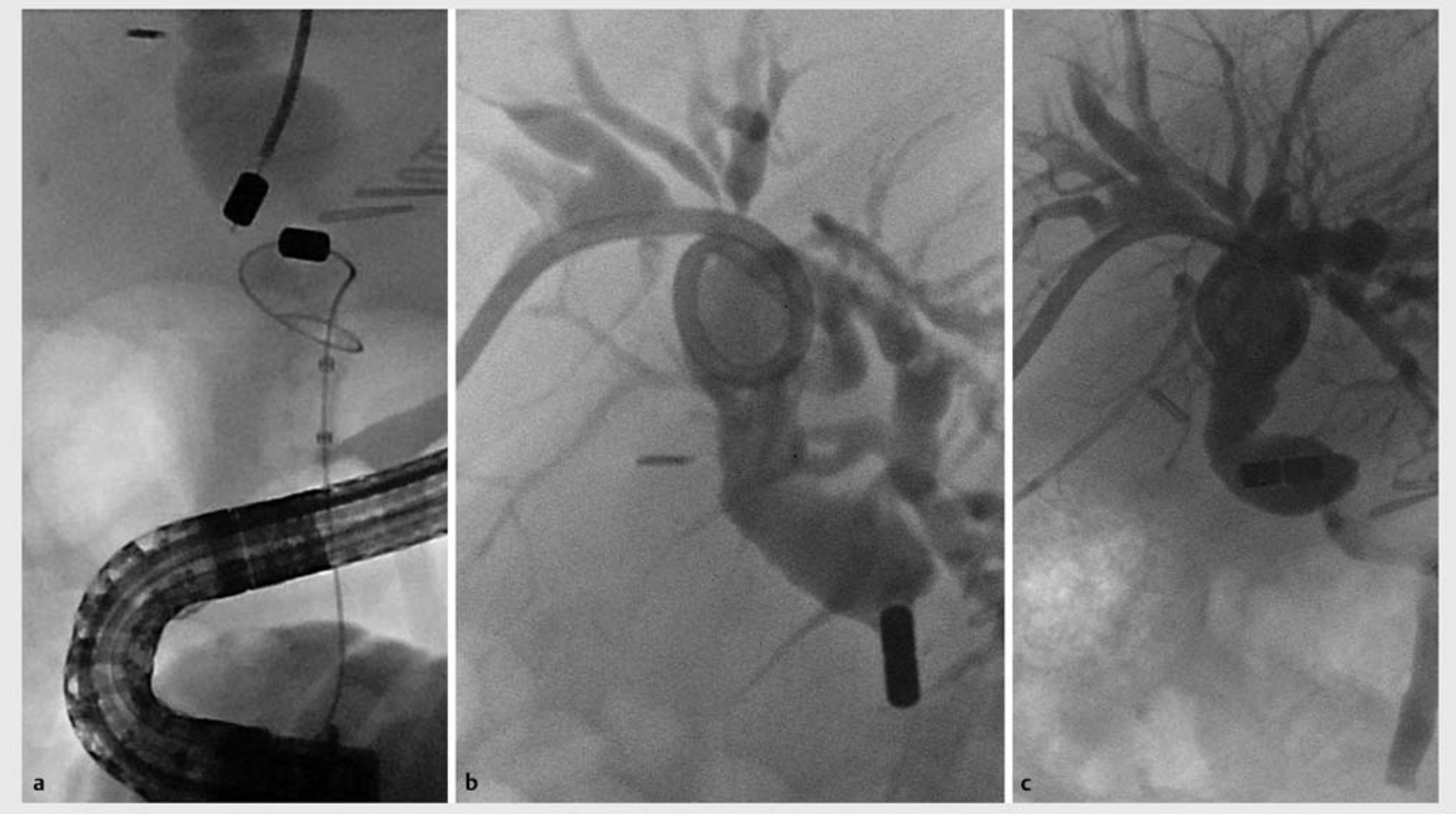

Fig. 1 Radiographic images showing: a the combined endoscopic and percutaneous insertion of two magnets to obtain recanalization of the anastomotic biliary stricture; $\mathbf{b}$ complete approximation of the magnets after 3 days; c proximal migration of the magnets on day 24 .

A 59-year-old man underwent orthotopic liver transplantation; liver re-transplantation was needed 24 hours later owing to primary liver failure. A large incisional hernia was repaired 5 years later.

Increases in his liver function tests were noted 6 years later and magnetic resonance cholangiography showed an anastomotic biliary stricture. During endoscopic retrograde cholangiopancreatography (ERCP), it was impossible to pass beyond the anastomotic biliary stricture, even with the aid of cholangioscopy (SpyGlass DS; Boston Scientific, Natick, Massachusetts, USA). Percutaneous negotiation of the biliary stricture also failed despite cholangioscopy. After multidisciplinary discussion, surgery was considered too risky owing to the previous

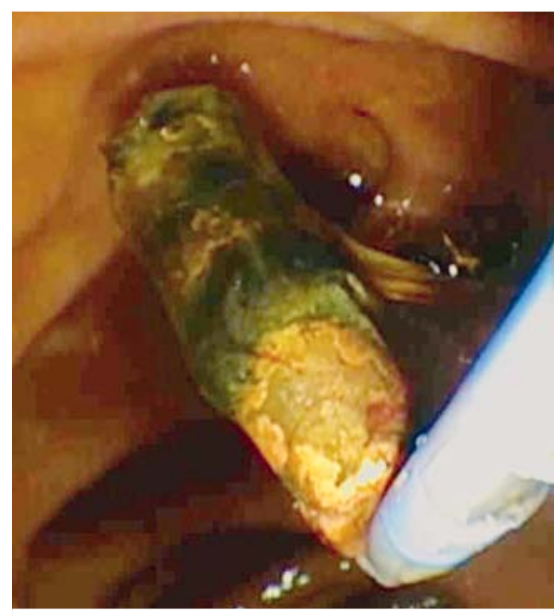

- Fig. 2 The migrated magnets were attracted with the tip of a modified catheter so that they could be removed.



- Fig. 3 Photograph of the removed magnets showing corrosion on one side. 


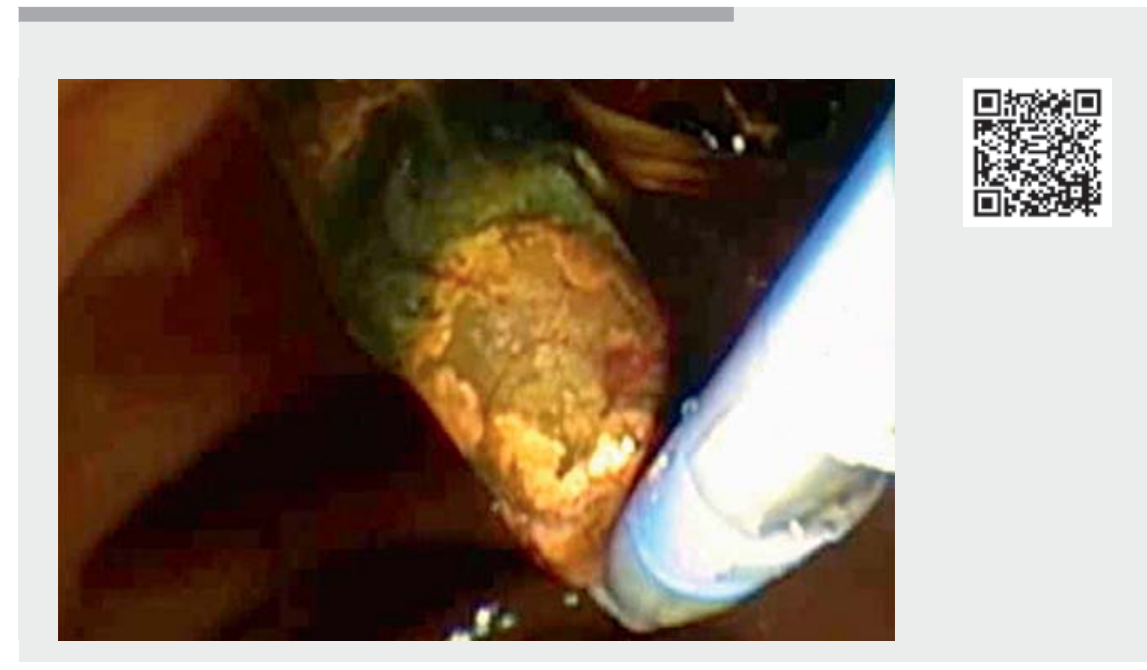

$\checkmark$ Video 1 Video showing the endoscopic removal of two magnets that had migrated above an anastomotic biliary stricture using a homemade, over-the-wire magnet retrieval system.

interventions and therefore magnetic compression anastomosis [1-4] was proposed; the patient signed a specific informed consent for compassionate use. The procedure involved the over-the-wire placement of two cylindrical $(7 \times 3 \mathrm{~mm})$ neodymium magnets (Cibas Srl, Milan, Italy) with a combined endoscopic and percutaneous approach ( $\mathbf{F i g . 1} \mathbf{a}$ ). After 3 days, the magnets were found to be approximated ( $\boldsymbol{F}$ Fig. $\mathbf{1} \mathbf{b}$ ) and the patient was discharged with a 10-Fr external drain. He underwent radiography every 3-4 days to detect migration of the magnets and, after 24 days, proximal migration and recanalization of the anastomotic biliary stricture was found to have occurred ( Fig.1 c). Removal of the magnets was not initially attempted owing to the tightness of the stricture and three plastic stents were placed.

Magnet removal was subsequently planned 2 months later. Grasping with a Dormia basket was considered to be dangerous owing to the risk of impaction. A homemade, over-the-wire "magnet retrieval" system was therefore created by inserting a paperclip into the tip of a steerable ERCP catheter ( $>$ Fig. 2). After the anastomotic biliary stricture had been dilated with a $6-\mathrm{mm}$ balloon, the magnets were extracted through the papilla using the homemade device ( $\triangleright$ Video 1). One magnet showed corrosion at one side ( $\mathbf{F i g . 3}$ ), but this was
Corresponding author

\section{Andrea Tringali, MD, PhD}

Digestive Endoscopy Unit, Dipartimento Scienze Mediche e Chirurgiche, Fondazione Policlinico Universitario A. Gemelli IRCCS, Università Cattolica del Sacro Cuore, Largo Agostino Gemelli, 8, 00168 Rome, Italy andrea.tringali@unicatt.it

\section{References}

[1] Ersoz G, Tekin F, Bozkaya H et al. Magnetic compression anastomosis for patients with a disconnected bile duct after living-donor related liver transplantation: a pilot study. Endoscopy 2016; 48: 652-656

[2] Jang SI, Lee KH, Yoon HJ et al. Treatment of completely obstructed benign biliary strictures with magnetic compression anastomosis: follow-up results after recanalization. Gastrointest Endosc 2017; 85: 1057-1066

[3] Parlak E, Koksal AS, Kucukay F et al. A novel technique for the endoscopic treatment of complete biliary anastomosis obstructions after liver transplantation: through-thescope magnetic compression anastomosis. Gastrointest Endosc 2017; 85: 841-847

[4] Li Y, Sun H, Yan X et al. Magnetic compression anastomosis for the treatment of benign biliary strictures: a clinical study from China. Surg Endosc 2020; 34: 2541-2550

\section{Competing interests}

Andrea Tringali is a consultant for Boston Scientific Corp. Ivo Boškoski is a consultant for Apollo Endosurgery, Cook Medical, and Boston Scientific Corp., he holds a research grant from Apollo Endosurgery, and is on the scientific board of EndoTools. Guido Costamagna is on the advisory board for Cook Medical, Olympus, and Ethicon, and holds a research grant from Boston Scientific Corp. and Apollo Endosurgery. The remaining authors declare that they have no conflict of interest.

The authors

Andrea Tringali ${ }^{1,2}$, Vincenzo Perri ${ }^{1,2}$, Ivo Boškoski $^{1,2}$, Alessandro Cina ${ }^{3}$, Guido Costamagna ${ }^{1,2} \odot$

1 Digestive Endoscopy Unit, Fondazione Policlinico Universitario A. Gemelli IRCCS, Rome, Italy

2 Centre for Endoscopic Research Therapeutics and Training (CERTT), Università Cattolica del Sacro Cuore, Rome, Italy

3 Radiology Department, Fondazione Policlinico Universitario A. Gemelli IRCCS, Rome, Italy

\section{Bibliography}

Endoscopy 2022; 54: E411-E412

DOI 10.1055/a-1559-1934

ISSN 0013-726X

published online 8.9.2021

(C) 2021. Thieme. All rights reserved.

Georg Thieme Verlag KG, Rüdigerstraße 14, 70469 Stuttgart, Germany

\section{ENDOSCOPY E-VIDEOS \\ https://eref.thieme.de/e-videos}



Endoscopy E-Videos is an open access online section, reporting on interesting cases and new techniques in gastroenterological endoscopy. All papers include a high quality video and all contributions are freely accessible online. Processing charges apply (currently EUR 375), discounts and wavers acc. to HINARI are available.

This section has its own submission website at https://mc.manuscriptcentral.com/e-videos 